\title{
Knowledge regarding postexposure prophylaxis of HIV among nurses
}

This article was published in the following Dove Press journal:

Nursing: Research and Reviews

27 April 2017

Number of times this article has been viewed

\section{Puja Sharma Dhital' \\ Sarojini Sharma ${ }^{2}$ \\ Pratik Poudel ${ }^{3}$ \\ Pankaj Raj Dhital ${ }^{4}$}

'Adult Health Nursing, Nepal Polytechnic Institute, College of Nursing, ${ }^{2}$ Adult Health Nursing, BP Koirala Memorial Cancer Hospital, ${ }^{3}$ Department of Radiology, College of Medical Sciences, Bharatpur, ${ }^{4}$ Department of Agricultural Extension and Rural Sociology, Agriculture and Forestry University, Rampur, Nepal
Correspondence: Puja Sharma Dhital Nepal Polytechnic Institute, College of Nursing, Bharatpur, Nepal Email pujash789@gmail.com
Abstract: Fifty nurses working in BP Koirala Memorial Cancer Hospital, Bharatpur, were selected by probability simple random sampling technique for determining the knowledge level about postexposure prophylaxis (PEP) of HIV among nurses during 2014. A descriptive design, semistructured self-administered questionnaire was used for the study. The study showed that $48 \%$ of respondents had knowledge on the meaning of PEP, only $39.39 \%$ respondents were aware of the first aid management getting needle prick injury, $60 \%$ were aware of the best time to start PEP of HIV and 56\% respondents had knowledge about the time schedule of HIV test after exposure. Although the respondents answered most of the questions correctly, they had knowledge deficit in certain areas. The respondents' knowledge in this regard needs to be improved with time-to-time awareness program and periodic training, which ultimately helps to decrease the transmission of disease and reduces mortality and morbidity.

Keywords: needle prick injury, transmission, PEP, HIV

\section{Introduction}

According to the World Health Organization (WHO), human immunodeficiency virus (HIV) infects cells of the immune system and destroys or impairs their function. Infection with HIV results in the progressive deterioration of the immune system. This leads to "immune deficiency" in infected human. When immune system could not fulfill its role of fighting infection and disease, it is then considered as deficient. The WHO and the United Nations Program on HIV and AIDS estimated 34 million people living with HIV in 2011. In the same year, $\sim 1.7$ million died of acquired immunodeficiency syndrome (AIDS) including 230,000 children, and 2.5 million people became newly infected. Similarly, more than two-thirds of new HIV infections are reported in SubSaharan Africa. ${ }^{1}$ Out of $90 \%$ of people with HIV, living in Asia and the Pacific, $49 \%$ of them are in India alone. ${ }^{2}$ In Nepal, HIV prevalence is $\sim 0.3 \%-0.2 \%$ over the past 5 years. There are about 40,720 people affected with HIV in Nepal. It was reported that among the 15-49 years old age group $0.23 \%$ are infected with HIV. But there is reduction in the number of new infections from 8039 in 2000 to 1408 in 2013. ${ }^{3}$

During the course of health care of patients, thousands of health care workers suffer accidental occupational exposures around the world. The WHO/International Labor Organization recommended the use of HIV postexposure prophylaxis (PEP) for prevention of HIV infection resulting from accidental injuries at workplaces. ${ }^{4}$ Various studies have shown a high prevalence of needlestick injuries in Nepal. ${ }^{5,6}$ However, the practice of reporting of needlestick injuries has not been well established in Nepal. 
Until now, PEP has been the only way to reduce the risk of HIV infection, if any health care worker gets exposed to HIV. PEP refers to the use of antiretroviral medications to reduce the risk of HIV transmission. Antiretroviral treatments (ARTs) given immediately after the accidental exposure can stop the dissemination of virus in the body and can decelerate infection establishment. ${ }^{7}$ The risk of HIV transmission is $\sim 0.3 \%$ after skin puncture. There have been rare reports of HIV transmission through exposure to mucous membrane (of eyes, nose or mouth) or abraded (broken) skin, and the risk is estimated to be $\sim 0.09 \%$. $^{7}$

PEP is a medical response to prevent transmission of pathogens after potential exposure. It is a comprehensive management procedure to minimize the risk of infection following potential exposure to blood-borne pathogens (HIV and hepatitis B virus [HBV]). ${ }^{8}$ It includes first aid, counseling, risk assessment, relevant laboratory investigations based on the informed consent of the exposed person and source and, depending on the risk assessment, the provision of short term (28 days) of antiretroviral drugs, along with follow-up evaluation. ${ }^{8}$ PEP for HIV exposure is best when started within the golden period of $<2$ hours but no later than 72 hours after exposure. The prophylaxis needs to be continued for 28 days. The National AIDS Control Organization makes efforts to ensure its free-of-cost availability at all antireteroviral therapy centers and integrated counseling and testing centers. ${ }^{7}$ Rapid tests of HIV are available in Voluntary HIV/AIDS Counseling, Testing and Referral sites in hospitals, ART centers and NGOs. There are $\sim 65$ ART service sites established in Nepal. These ART sites provide antiretroviral drugs for treating and preventing HIV infection. ${ }^{9}$ As basic regimen two-drug combinations of ZDV or AZT (zidovudine)+3TC (lamivudine) and as expanded regimen three-drug combinations, two nucleosides $(\mathrm{ZDV}+3 \mathrm{TC})+\mathrm{LPV} / \mathrm{r}$ (lopinavir/ritonavir) are recommended for adults. ${ }^{7}$

Nurses must have knowledge about PEP and the risk of transmission of HIV as they are the most commonly exposed health care workers to needle prick injuries and contact with infectious body fluids. It is thus important to train them to protect themselves from the professional health hazards. There is however little information available in Nepal on the knowledge about PEP and transmission risk of HIV among nurses. Hence, this study was carried out to know the knowledge of nurses regarding PEP of HIV.

\section{Materials and methods}

The descriptive design was used to find out the level of knowledge regarding PEP of HIV among nurses of BP Koirala Memorial Cancer Hospital (BPKMCH) in December 2014. A total of 50 nurses were selected from 10 different wards as a sample for the study using the probability simple random sampling technique. Five nurses were selected from each ward. The study populations were either proficiency certificate-level (PCL) nurses or post basic bachelor of nursing (PBBN) nurses working at BPKMCH. A semistructured self-administered questionnaire was developed. The questionnaire consisted of a sociodemographic status of the respondent and the knowledge related to PEP of HIV. The reliability of the instrument was established by pretesting the instrument among nurses of similar setting ( $10 \%$ of the total sample size). The validity and reliability of research instrument was maintained by reading the relevant literature and reviewing previous study instruments used by other researchers, consultation and discussion with advisory committee members. Approval to conduct the study was obtained from the hospital academic committee of BPKMCH as well as the administrative authority of Nepal Polytechnic Institute, Nursing College. Verbal consent was taken from all respondents. Confidentiality was maintained by not disclosing the name of respondents. All collected data were entered in Microsoft Excel 2007 and analyzed by using Statistical Package for Social Sciences (SPSS 16).

\section{Results}

The sociodemographic status of the respondents is shown in Table 1 . The age range of respondents was 20-35 years, with $38.0 \%$ of respondents between the ages of 20 and 33 years. A majority of respondents $(56.0 \%)$ had academic qualifications of PCL of nursing, and $38.0 \%$ of the respondents had completed Bachelor of Nursing, whereas very few $(6.0 \%)$ of the respondents had completed BSc Nursing. Out of 50 respondents, most of them had worked in the hospital for at least 1 year. Approximately $56.0 \%$ of respondents had $>3$ years of working experience. Those who have worked for 2-3 years were $20.0 \%, 0-1$ year were $18.0 \%$, and $<1$ year were only $6.0 \%$.

The majority $(66.0 \%)$ of the respondents have previous knowledge about PEP of HIV (Table 2). Respondents identified different sources of information about PEP, which included in-service education $(9.09 \%)$, self-learning (63.63\%) and media (18.18\%). But none of the respondents have received any training on PEP of HIV. Approximately $40.0 \%$ respondents answered the correct meaning of PEP as short-term medical therapy to prevent HIV infection. Approximately $74.0 \%$ of the respondents know that PEP drugs are available free of cost in Nepal, and $86.0 \%$ of the respondents answered that it is available at ART clinic (Table 2).

Hundred percent of the respondents said that nurses are more at risk of contracting HIV while giving injection 
Table I Sociodemographic characteristics of study population

\begin{tabular}{ll}
\hline Variables & $\begin{array}{l}\text { Frequency, } \\
\mathbf{N}=\mathbf{5 0}(\%)\end{array}$ \\
\hline Age range (years) & \\
$20-23$ & $19(38.0)$ \\
$24-27$ & $17(34.0)$ \\
$28-31$ & $9(18.0)$ \\
$32-35$ & $5(10.0)$ \\
Qualification & \\
Proficiency certificate level & $28(56.0)$ \\
Post basic nursing & $19(38.0)$ \\
BSc nursing & $3(6.0)$ \\
Working experience (years) & \\
$0-1$ & $9(18.0)$ \\
I-2 & $3(6.0)$ \\
$2-3$ & $10(20.0)$ \\
$>3$ & $28(56.0)$ \\
\hline
\end{tabular}

Table 2 Respondents' awareness regarding PEP

\begin{tabular}{ll}
\hline Variables & $\begin{array}{l}\text { Frequency, } \\
\mathbf{N}=\mathbf{5 0}(\%)\end{array}$ \\
\hline $\begin{array}{l}\text { Previous knowledge about PEP } \\
\text { Yes }\end{array}$ & $33(66.0)$ \\
No & $17(34.0)$ \\
Source of information & \\
Training & $0(0.00)$ \\
In-service education & $3(9.09)$ \\
Self-learning & $21(63.63)$ \\
Media & $6(18.18)$ \\
Others (Internet and coworkers) & $7(21.21)$ \\
Awareness about hospital protocol & \\
Aware of the hospital protocol & $49(98.0)$ \\
Not aware of the hospital protocol & $1(2.0)$ \\
PEP is short-term medical therapy to & $24(48.0)$ \\
Prevent HIV infection & \\
PEP is available with free of cost in Nepal & $37(74.0)$ \\
PEP is available at ART clinic & $43(86.0)$ \\
\hline
\end{tabular}

Note: ${ }^{\text {Multiple response. }}$

Abbreviations: ART, antiretroviral treatments; PEP, postexposure prophylaxis.

and handling body fluids (Table 3). The result showed that more than half $(66.0 \%)$ of the respondents were exposed to accidental sharp/needlestick injury, whereas $44.0 \%$ of the respondents had body fluid splashes in their eyes. In the study, regarding the knowledge on the first aid management after getting needle prick injury, only $39.39 \%$ of the respondents correctly answered, that is, wash the site with soap and water. Similarly, $95.45 \%$ of the respondents correctly responded that exposed eye should be irrigated immediately with water or normal saline if they had body fluid splashes in their eyes (Table 3). Fifty-six percent of the respondents answered correctly that the risk for transmission of HIV is low in case of contact with mucous from an HIV-infected patient to the eye and mouth, and $84.0 \%$ of the respondents said that transmission of HIV is high in case of deep injuries by cut
Table 3 Respondents knowledge on exposure, immediate action after exposure and risk of contracting and transmission of HIV

\begin{tabular}{ll}
\hline Variables & $\begin{array}{l}\text { Frequency, } \\
\text { N=50 (\%) }\end{array}$ \\
\hline $\begin{array}{l}\text { Exposure } \\
\text { Sharp/needlestick injury }\end{array}$ & $33(66.0)$ \\
Body fluid splashes in the eyes & $22(44.0)$ \\
Immediate action after exposure & \\
Wash the site with soap and water after & $13(39.39)$ \\
getting needle prick injury & \\
Irrigate the exposed eye immediately with & $21(95.45)$ \\
water or normal saline after body fluid & \\
splashes in the eyes & \\
Risk of contracting HIV is at giving injection & \\
and handling body fluids & $50(100.0)$ \\
Low risk for transmission of HIV by contact \\
with mucous from an HIV-infected patient to \\
the eye and mouth & $28(56.0)$ \\
High risk for transmission of HIV by deep \\
injuries caused by cut with the sharp object \\
used in an HIV-infected person \\
High-risk body fluid
\end{tabular}

Notes: aultiple response; $\checkmark$ indicates correct answers.

Abbreviation: HIV, human immunodeficiency virus.

with the sharp object used in an HIV-infected person (Table 3 ). Seventy percent of the respondents correctly identified that amniotic fluid is considered as high-risk body fluid for HIV transmission.

Sixty-six percent of the respondents answered PEP of HIV consisting of three-drug regimen, whereas $34.0 \%$ of the respondents answered two-drug regimen (Table 4). Here both of the answers are correct. Less than half (40.0\%) of the respondents correctly answered that the drugs used for PEP in basic regimen are zidovudine and lamivudine. Only $42.0 \%$ of the respondents correctly identified zidovudine, lamivudine and lopinavir/ritonavir as the antiretroviral drugs used for PEP in extended regimen. But $40.0 \%$ of the respondents said that zidovudine, stavudine and efavirenz were drugs used for PEP (Table 4), which was incorrect.

Forty-four percent of the respondents have correct knowledge about correct dosages of basic regimen, which are zidovudine $300 \mathrm{mg}$ and lamivudine $150 \mathrm{mg}$. The majority of respondents $(46.0 \%)$ did not know the correct dose of basic regimen and answered zidovudine $300 \mathrm{mg}$, lamivudine 150 $\mathrm{mg}$ and lopinavir/ritonavir $400 \mathrm{mg} / 100 \mathrm{mg}$ (Table 4). Fortyfour percent of the respondents have knowledge about the correct dosages of extended regimen, which are zidovudine 
Table 4 Respondents' awareness about drug regimen, PEP drugs and dosages of drugs

\begin{tabular}{|c|c|}
\hline Variables & $\begin{array}{l}\text { Frequency, } \\
\mathrm{N}=50 \text { (\%) }\end{array}$ \\
\hline \multicolumn{2}{|l|}{ Drug regimen ${ }^{\mathrm{a}}$} \\
\hline Two-drug regimen $\checkmark$ & $17(34)$ \\
\hline Three-drug regimen $\checkmark$ & $33(66)$ \\
\hline \multicolumn{2}{|l|}{ Drugs used for PEP in basic regimen } \\
\hline Zidovudine, lamivudine and lopinavir/ritonavir & $27(54.0)$ \\
\hline Zidovudine and lamivudine $\checkmark$ & $20(40.0)$ \\
\hline \multicolumn{2}{|l|}{ Drugs used for PEP in extended regimen } \\
\hline Zidovudine, lamivudine and lopinavir/ritonavir $\checkmark$ & $21(42.0)$ \\
\hline Zidovudine, stavudine and efavirene & $20(40.0)$ \\
\hline \multicolumn{2}{|l|}{ Dosages of basic regimen } \\
\hline $\begin{array}{l}\text { Zidovudine } 300 \mathrm{mg} \text {, lamivudine } 150 \mathrm{mg} \text { and } \\
\text { lopinavir/ritonavir } 400 \mathrm{mg} / 100 \mathrm{mg}\end{array}$ & $23(46.0)$ \\
\hline Zidovudine $300 \mathrm{mg}$ and lamivudine $150 \mathrm{mg} \checkmark$ & $22(44.0)$ \\
\hline \multicolumn{2}{|l|}{ Doses of extended regimen } \\
\hline $\begin{array}{l}\text { Zidovudine } 300 \mathrm{mg} \text {, lamivudine } 150 \mathrm{mg} \text { and } \\
\text { lopinavir/ritonavir } 400 \mathrm{mg} / 100 \mathrm{mg}\end{array}$ & $22(44.0)$ \\
\hline $\begin{array}{l}\text { Zidovudine } 200 \mathrm{mg} \text {, stavudine } 150 \mathrm{mg} \text { and } \\
\text { efavirene } 500 \mathrm{mg}\end{array}$ & $22(44.0)$ \\
\hline
\end{tabular}

Notes: Multiple response; $\checkmark$ indicates correct answers.

Abbreviation: PEP, postexposure prophylaxis.

$300 \mathrm{mg}$, lamivudine $150 \mathrm{mg}$ and lopinavir/ritonavir 400 $\mathrm{mg} / 100 \mathrm{mg}$, whereas $44.0 \%$ of the respondents answered the incorrect dosages of extended regimen, that is, zidovudine $200 \mathrm{mg}$, stavudine $150 \mathrm{mg}$ and efavirene $500 \mathrm{mg}$ (Table 4).

The majority of respondents $(60.0 \%)$ knew that the best time to start PEP is within 2 hours (Table 5). Fifty-eight percent of the respondents correctly responded that beyond 72 hours, it is ineffective to start PEP. Fifty percent of the respondents did not know the duration of PEP and 50.0\% respondents knew that the duration of PEP 28 days. Seventy percent of the respondents correctly answered that nausea is the common side effect of PEP, $66.0 \%$ answered as headache, $62.0 \%$ answered as diarrhea and $22.0 \%$ answered as muscular pain. Similarly, $44.0 \%$ of the respondents considered blurred vision as the common side effect (Table 5). More than half (56.0\%) of the respondents answered correctly that the time schedule of HIV test after exposure is at baseline, 6 weeks, 3 months and 6 months (Table 5).

\section{Discussion}

Knowledge and awareness about PEP is an important factor for reducing the risk of transmission of HIV within the workplace. Nurses face patients with known and unknown HIV status. Thus, there is really a need on the knowledge about PEP among nurses. The study revealed that the majority of the respondents have previous knowledge about PEP of HIV. Regarding respondent's knowledge, $<50 \%$ had knowledge on the meaning of PEP. This finding is concordant with another
Table 5 Respondents' knowledge about the duration of PEP

\begin{tabular}{|c|c|}
\hline Responses & $\begin{array}{l}\text { Frequency, } \\
\mathbf{N}=50 \text { (\%) }\end{array}$ \\
\hline $\begin{array}{l}\text { The best time to start PEP of HIV is within } 2 \text { hours of } \\
\text { exposure }\end{array}$ & $30(60.0)$ \\
\hline $\begin{array}{l}\text { Ineffective time to start PEP of HIV is beyond } 72 \\
\text { hours }\end{array}$ & $29(58.0)$ \\
\hline Duration of PEP of HIV is 28 days & $25(50.0)$ \\
\hline \multicolumn{2}{|l|}{ Side effects of PEP drugs ${ }^{a}$} \\
\hline Nausea $\checkmark$ & $35(70.0)$ \\
\hline Muscular pain $\checkmark$ & II (22.0) \\
\hline Diarrhea $\checkmark$ & $31(62.0)$ \\
\hline Headache $\checkmark$ & $33(66.0)$ \\
\hline Blurred vision & $22(44.0)$ \\
\hline $\begin{array}{l}\text { Time schedule of HIV test after exposure at } \\
\text { baseline, } 6 \text { weeks, } 3 \text { months and } 6 \text { months }\end{array}$ & $28(56.0)$ \\
\hline
\end{tabular}

Notes: Multiple response; $\checkmark$ indicates correct answers

Abbreviations: HIV, human immunodeficiency virus; PEP, postexposure prophylaxis.

study done in Ethiopia, which showed that $72.0 \%$ of the respondents believed that PEP reduces the likelihood of HIV infection after exposure. ${ }^{10}$

Self-learning and Internet/coworkers were the most common sources of information about PEP for respondents. Not even a single respondent had received the training on PEP of HIV. This shows that the respondents are self-conscious about HIV risk, but PEP is a topic least discussed and not often seen as the component of comprehensive health care for HIV. ${ }^{11}$ A study carried out in tertiary care center of Nepal showed that nurses had the maximum needlestick injuries $(76.7 \%){ }^{6}$ Approximately $62 \%-88 \%$ of the needlestick injuries can be prevented through technology and training. ${ }^{12}$

Majority of the respondents knew that the drugs used in PEP are available free of cost in ART clinic in Nepal. Among the respondents working in Sungai Petani hospital, only $67.0 \%$ had knowledge and only $32.0 \%$ of doctors and $23.0 \%$ of the nurses had of idea about the cost of these drugs. ${ }^{13}$

All of the respondents have at least one accidental exposure. The exposure was due to sharp/needlestick injury and body fluid splashes in the eyes. All respondents knew the risk of contracting HIV was at giving injection and handling body fluids, and the majority of them knew the factors related to low and high risk for transmission of HIV. Only one-third of the respondents knew the first aid management after getting needle prick injury, whereas the majority of them knew the immediate action after body fluid splashes in their eyes. This result is supported by a study which showed that $84.6 \%$ of the respondents correctly stated that washing the site with soap and water was the first-aid measure to be followed. ${ }^{14}$ Lack of knowledge and ignorance, for example, not wearing gloves and recapping of needles using a single-handed 
technique, may be the major reasons after needlestick injury. Wearing gloves during any procedure is considered to be an important line of defense. Needlestick injuries were found higher among nurses who do not wear gloves while working. ${ }^{15}$ Further research showed that nurses working in BPKMCH were less aware of the first aid management in comparison to the previous study. ${ }^{16}$

Most of the respondents have knowledge on body fluids, which are considered as high risk for HIV transmission. A similar finding was reported in Medical College in West Bengal of India, which showed that pleural fluid was considered infectious by $53 \%$, cerebrospinal fluid by $55 \%$ and synovial fluid by $37 \%$, whereas $53 \%$ considered peritoneal fluid, $79 \%$ breast milk, $14 \%$ saliva, $27 \%$ urine, $27 \%$ feces, and $21 \%$ vomits to be infectious. ${ }^{16}$

This study on the knowledge of the respondents regarding the basic and extended regimens of PEP of HIV showed that less than half of the respondents know that the drugs used for PEP are in both the basic and extended regimens. Knowledge about the basic and expanded regimens of PEP was reported to be $35.19 \%$ and $20.06 \%$ in resident medical officers, respectively. ${ }^{17}$ Regarding the respondent's knowledge on the time for initiation and the availability of PEP of HIV, $60.0 \%$ answered that the best time to start PEP of HIV is within 2 hours of exposure. This finding was supported by a study which showed that $68.5 \%$ respondents had the idea when it should be started. ${ }^{14}$ Similarly, in Sungai Petani hospital, $73.0 \%$ of doctors and $65.0 \%$ of nurses knew that when PEP of HIV should be started. ${ }^{13}$

Regarding the duration of drugs of PEP of HIV, the study showed that half of the respondents had the idea that PEP of $\mathrm{HIV}$ is prescribed for 28 days. This finding is consistent with the study conducted in Gondar, northwest Ethiopia. ${ }^{18}$ The study reported that $72.8 \%$ of the respondents had knowledge about the length of time to take PEP of HIV. About half of the respondents knew the test schedule after exposure. The study further showed that BPKMCH nurses were more aware of the postexposure test than that of the study conducted in India, which showed that only $2 \%$ of the health care workers had the idea about test schedule after exposure. ${ }^{19}$

These findings show that the knowledge levels of nurses are average and thus require training on the protocol of hospital regarding HIV risk factors and PEP of HIV, and also hospital authority should provide PEP drugs under accidental exposure to infectious body fluids.

\section{Conclusion}

Most of the nurses working on BPKMCH, Bharatpur, had an average level of knowledge regarding PEP of HIV. Lack of knowledge and ignorance regarding the primary prevention of occupational exposures was observed among the nurses. There should be counseling of nurses about the accidental exposure if happened and PEP, and also that the drugs are not $100 \%$ effective in preventing HIV. The drugs have to be started within 2 hours or as soon as possible and should be taken for a total of 4 weeks. Also, it has to be made readily available in the hospital. Thus, policy makers of BPKMCH should provide in-service education and training for nurses about PEP of HIV focusing on drug regimen and duration of PEP, which will help to prevent transmission of HIV in workplace. Also, policy makers in the health sector should scale up PEP services to avoid occupationally acquired HIV infection in workplace and reduce HIV transmission.

\section{Recommendations}

1. Regular education and training for nurses in frequent intervals should be carried out.

2. Hospital management should document the accidental exposure of nurses to the risk factor of HIV.

3. The guideline for precaution measures and disseminate among nurses should be prepared.

4. Drugs for PEP should be made available in every hospital, and in cases treatment should be immediately initiated.

\section{Acknowledgment}

The authors heartily acknowledge the members of academic committee, Dr. Vijaya Chandra Acharya and Mrs. Sarojini Sharma of BP Koirala Memorial Cancer Hospital, Bharatpur, Chitwan, for providing the opportunity to conduct the study.

\section{Disclosure}

The authors report no conflicts of interest in this work.

\section{References}

1. World Health Organization (WHO). HIV AIDS, Post Exposure Prophylaxis. 2013.

2. AIDS 2014. Factsheet HIV and AIDS in Asia and the Pacific. 20th International AIDS Conference. Melbourne, Australia. July 20-25, 2014.

3. National Center for AIDS \& STD Control (NCASC). Country Progress Report on HIV/AIDS response, Nepal. 2014.

4. World Health Organization (WHO)/International Labour Organization (ILO). Joint ILO/WHO guidelines on health services and HIV/AIDS 2005.

5. Gurubacharya DL, Mathura KC, Karki DB. Knowledge, attitude and practices among health care workers on needle-stick injuries. Kathmandu Univ Med J (KUMJ). 2003;1(2):91-94.

6. Singh B, Paudel B, Kc S. knowledge and practice of health care workers regarding needle stick injuries in a tertiary care center of nepal Kathmandu Univ Med J. 2015;51(3):230-233.

7. National Center for AIDS \& STD Control (NCASC). National AntiRetroviral Therapy Guidelines. 2009.

8. Sharma A, Marfatia YS, Ghiya R. Post-exposure prophylaxis for HIV Indian J Sexual Transm Dis AIDS. 2007;28(2):61-68. 
9. National Center for AIDS \& STD Control (NCASC). National Consolidated Guideline for Treating and Preventing HIV in Nepal.2014.

10. Tebeje B, Hailu C. Assessment of HIV post-exposure prophylaxis use among health care worker of governmental health institutions in Zimma zone, Oromiya region, Southwest Ethiopia. Ethiop J Health Sci. 2010;20(1):55-64.

11. Owolabi RS, Alabi P, Ajayi S, Daniel O, et al. Knowledge and practice of post-exposure prophylaxis (PEP) against HIV infection among health care providers in a tertiary hospital in Nigeria. $J$ Int Assoc Physicians AIDS Care (Chic). 2012;11(3):179-183.

12. OSHA, Department of Labor, Occupational Safety,and health Administration. Occupational exposure to bloodborne pathogens, needle stick, and other sharps injuries: final rule. Fed Regis. 2001;66:5318-5325.

13. Bairy KL, Ganaraja B, Indira, B, Thiyagar N, Choo CM, See CK. Awareness of post-exposure prophylaxis guidelines against occupational exposure to HIV in hospital Sungai Petani. Med J Malaysia. 2005;60(1):10-14.

14. Foster TM, Lee MG, McGaw CD, Frankson MA. Prevalence of needle stick injuries and other high risk exposures among healthcare workers in Jamaica. West Indian Med J. 2010;59(2):153-158.
15. Sharma R, Rasania SK, Verma A, Singh S. Study of prevalence and response to needle stick injuries among health care workers in a tertiary care hospital in Delhi, India. Indian J Community Med. 2010;35(1): 74-77.

16. Mukherjee S, Bhattacharya A, Sharma SB, Goswami DN, Ghosh S, Samanta A. Knowledge and practice of standard precautions and awareness regarding post-exposure prophylaxis for HIV among interns of a medical college in West Bengal, India. Oman Med J. 2013;28(2):141-145.

17. Baheti AD, Tullu MS, Lahiri KR. Awareness of health care workers regarding prophylaxis for prevention of transmission of blood-borne viral infections in occupational exposures. Al Ameen JMed Sci. 2010;3: 79-83.

18. Mathewos B, Birhan W, Kinfe S, et al. Assessment of knowledge, attitude and practice towards post exposure prophylaxis for HIV among health care workers in Gondar, North West Ethiopia. BMC Public Health. 2013;13(1):508.

19. Pathak R, Kahlon AS, Ahluwalia SK, Sharma S, Bhardwaj R. Needle stick injury and inadequate post exposure practices among health care workers of a tertiary care centre in rural India. Int J Collab Res Intern Med Public Health. 2012;4(5):638-648.
Nursing: Research and Reviews

\section{Publish your work in this journal}

Nursing: Research and Reviews is an international, peer-reviewed, open access journal publishing original research, reports, reviews and commentaries on all aspects of nursing and patient care. These include patient education and counseling, ethics, management and organizational issues, diagnostics and prescribing, health outcomes, economics and
Dovepress

resource management, improving patient safety in all settings. The manuscript management system is completely online and includes a very quick and fair peer-review system. Visit http://www.dovepress. com/testimonials.php to read real quotes from published authors. 